\title{
Young Arab Women at the Crossroads between the Traditional and the Modern: Analysis of Life Stories of Arab Muslim Students Who Have Left Home to Achieve Higher Education
}

\author{
Zeev W. Greenberg
}

Tel-Hai College

Dafna M. Sagiv-Reiss

\author{
Tel-Hai College \\ Upper Galilee \\ 12210 Israel \\ Email address: dafnasagiv@yahoo.com
}

\section{Doi:10.5901/mjss.2013.v4n2p143}

\begin{abstract}
This article deals with young Arab Muslim women who have left their homes in order complete their academic education. An analysis of their life stories demonstrates the influence of the nuclear family in encouraging their studies and the expectations to be more independent than their mothers. In addition, the stories present the difficulties these students experience in the personal context, difficulties of being cut off from their families. Moreover, difficulties in the social and cultural contexts, in their insecurity at using the Hebrew language, and threatening difficulties which stem from a sense of being unsuited to the new academic world especially as being a woman and coming from a minority group. Furthermore, their stories reveal difficulties which derive from gender construction and informal systems of control and supervision initiated by male students in institutions of higher learning. The findings also attest to the practices of resistance, opposition and coping with this complex reality by these young women. (157 words)
\end{abstract}

Key words: Gender; Life Stories; Arab Muslim women; Higher Education

\section{Young Arab Women at the Crossroads Between the Traditional and the Modern}

This article deals with the life stories of young Muslim Arab women who have left home in order to obtain higher education. They must live outside their homes independently in the place where they are studying. The life stories of these students illustrate the difficulties they must face as they stand at the crossroads between a traditional patriarchal society and a realty in which modernity is salient. In addition, hovering above them are the quandaries, the tensions and the dilemmas they must cope with as young women in a traditional society which in the process of change.

The Arabs in Israel constitute an ethnic religious and traditional minority. The structure of Arab society in general and that of Israeli Arabs in particular is patriarchal and organized into extended families. This society is in a process of change which is, in essence, movement from a traditional society to a modern society. Young men and women who are leaving to gain a higher education provide one example of these changes in Arab society (Dwairy, 1998; Abu-Baker, 2005). The reasons for choosing Israeli academic institutions are many, the most important of which are the proximity to their homes, the learning tracks and training which suit their areas of interest, and their aspirations and beliefs that studies in institutions of higher education in Israel will make it easier for them to be integrated in the employment market in Israel upon completion of their studies.

Much research has investigated the realm of higher education among Arabs in Israel (Al-Haj, 1996; Seginer, 2001; Pesta-Schubert, 2005; Gamliel and Kahan, 2005). These studies indicate the obstacles which stand in their way after they have been accepted into academic institutions. The studies examine the achievements of Arab students in comparison to other minorities and in comparison to the Jewish population. Some even deal with aspects of gender and investigate the effects of higher learning on changes in self-perception among Arab women students. The research has identified processes of openness, changes in modes of thinking, and a rise in self-esteem and in aspirations for equality and independence among young Arab men and women who are studying in Israeli academic institutions. 


\subsection{The present research}

This article focuses on the special difficulties experienced by Arab women students who have left home and are living far from their families and their villages in order to study in institutions of higher learning. The first section of the article will present concepts which describe the characteristics of Arab society and the changes taking place in this society, and it will refer to previous studies which illustrate the special difficulties of Arab women students in their meeting with the academic world; the significance of the nuclear family for these students; the difficulty in leaving home and family; and coping of many of them for the first time in their lives as independent adults in a new and alien space which is unknown to them. The findings of the research will focus on the special difficulties of women students and how they deal with these situations, the sources of which lie in roles of supervision and social control applied by the men in a patriarchal society in order to control women's activities and to dominate their bodies. The findings show the feelings of the students and their practices of resistance to these situations. In the last section of the article, there is a discussion of the practical and theoretical aspects associated with the students' exit from their homes and coping in the private and group contexts with the array of pressures and gender tensions involved in their act.

\section{Theoretical Background}

\subsection{Higher Education among Israeli Arabs}

Much research has demonstrated the association between higher education and employment among the Arab population in Israel (Shanel and Sofer, 2007; Sheinin, 2010). Since the 1980s, the number of Arab students studying in institutions of higher learning in Israel has increased steadily (Seginer\&Noyman, 2005). In 1970,2.3\% of the Arabs in Israel had studied in institutions of higher education, in the early 1980 s the number had risen to $7.7 \%$ and at the beginning of the $1990 \mathrm{~s}$, the number of Arab students rose to about $10 \%$ of the total number of students in institutions of higher learning. At the end of the first decade of the $21^{\text {st }}$ century, Arab students compose $13 \%$ of the total number of students in institutions of higher education. Thus, the tendency towards an increasing rate of Arab students studying in academic institutions is continuing and permanent.

Corresponding to the general increase in Arab students, the number of Arab women students in institutions of higher education is also growing. If, in 1990 , women students made up only $39.5 \%$ of the total number of Arab students in higher educational institutions, in 2002 the percentage of women students had grown to $50.8 \%$ and in 2005 , this trend continued and the percentage of women students had risen to $54.1 \%$. In $2008,58 \%$ of Arab students of higher education were women (Panso, Statistical Abstract of Israel, 2009).

The entry of Arab women in institutions of higher learning in Israel is accompanied by difficulties stemming from the gaps between Jews and Arabs in entitlement to a Matriculation Certificate and accessibility to higher education is longterm (Abu-Asba, 2001; Bolotin-Chachashvili, Shavit and Ayalon, 2002; Weiner and Levy, 2007; Dagan \&Buzaglo, 2007). An additional difficulty for Arab students is coping with their studies in Hebrew which is studied in Arab high schools but which they are not accustomed to as a spoken language. This is expressed as problems in reading, writing and understanding what is said in lectures.

There is additional distress stemming from cultural differences and from the sense of alienation felt by the students in a strange and unknown environment, difficulties with the language used in academic institutions, the fact that Arab students are not acquainted with the organization and rules of these institutions, the social isolation and the problems involved in finding a place to live and a place of employment. It may be assumed that the national identity of Arabs studying in Israeli institutions also affects these feelings.

Pesta-Schubert (2005) characterizes this as preserving the state of colonialism in the gaps between the achievements of Jewish and Arab students. She argues that discussion of majority-minority relations, the exclusion by the majority of the minority from knowledge and education are part of the system of control. She maintains that the academic debate confirms this dependence of the minority on the majority and does not undermine it. Moreover, Pesta-Schubert claims (2005) that the public-political discussion pushes aside the story of private coping of the minority student with higher learning. Among the subjects which are missing from this discussion, we may cite the student's coping with modes of thinking which are different from those s/he knows, the effect of the studies on the relations between the student (the learner) and his/her community (from which s/he has left for his/her studies and to which s/he will return upon completion) and the tensions between the traditional and the modern. 
This research contributes to the missing discussion as it investigates the life stories of these students, who make their "voices" heard and return the focus of discourse to the personal. As such, it deals with the gender aspects of going out into independent life, among women of the minority group. Thus, the stories which will be presented deal with "double marginality" (Rapoport, 1993) by the very fact that they are told by women who belong to a minority ethnic group as well as having membership in a weakened gender group, in a traditional patriarchal society. The life stories of the women students illustrate the special difficulties they must deal with when aiming to build their future, to obtain education and to leave the circle of gender dependence which characterizes the traditional patriarchal society from which they have come.

\subsection{Characteristics of a Collectivist Traditional Society}

Arab society is characterized as a traditional patriarchal society identified with collective traditional societies located in the Middle East, Asia, and Africa (Haj Yahia 1994; Efrati, 2004; Triandis, Bontempo, Villareal, Assai \& Lucca, 1988). The significant distinction between modern and traditional societies lies in the relations between the individual and the society. Traditional society is characterized by the superiority of the society over the individual and in the significance of the primary membership group, and first and foremost, in the family, with its variety of definitions, over the individual (Shawder and Brown, 1984). The obligation of the individual to fulfill the needs of the extended family, the clan and the tribe, and to meet their expectations are important for the definition of his/her identity (Markus \&Kitayama, 1991; Matsumoto,Takeuchi, Andayani, Kouznetsova and Krupp, 1998).

Fulfilling the rules and customs of the family contributes a sense of the individual's belonging to the society and harmonious existence of the individual with the collective. At times, this feelings are inclined to give up their personal goals and means for the sake of group goals (Triandis et al., 1988). The source of this framework is in the close connection between the survival, the success and the growth of the family, the clan and the tribe as a social body, and those of the individual (Bontempo, Lobel\&Triandis, 1990; Stephens, Markus, Hazel and Townds, 2007).

In collectivist tribal cultures, the image of the cohesive self predominates, according to which an individual views himself as part of a social relationship and believes that his/her behavior is dependent on the thoughts, the feelings and the actions of others. Relations in collectivist Arab society are based on imitation, obedience and accommodation of the individual's expectations to the expectations of the society from which s/he comes (Awwad, 2001; Kitayman, 1994). Similarly, the young Arab woman acts in accord with the social norms and not according to her wishes or personal qualities (Ya'ar\&Shavit, 2001).

Therefore, Weiner-Levy (2006) in her research on Druze women, points out that hiding thoughts and private feelings imitation of others' behavior and obedience to them are perceived as imperative, positive and empowering; agreement or submission to the other are not signs of weakness but rather indications of acceptance, self-control and maturity (Ibid., p. 9). Seginer (2001) indicates that there is little room in these societies for personal choice. Thus, it can be assumed that the demand in a traditional society for socially accepted behaviors plays a significant role, primarily among young women who leave the borders of the collective for other areas which are characterized as modern.

\subsection{Processes of Change in Arab Society}

More than seven hundred thousand Arabs live in the Galilee and Arab society there is defined as a traditional society in change (Haj Yahia, 1994; Bader-Aref, 1995; Kulik\& Ryan, 2005). The social changes are for the most part structural and functional. Many settlements which were villages in the past, now have characteristics of urban planning, such as multistorey buildings, and organized planning leads to the separation of areas in accord with their function (Hamisi, 2007); economic and employment changes and primarily, a reduction in agricultural work and the development of small businesses in the villages (Shanel\&Sofer, 2007).

The processes of change which Arab society is undergoing correspondingly affect the structure of the family. In the past three decades, there has been a clear trend towards later marriages among women, a rise in the age of women giving birth and a decrease in the number of children per family (Haider, 2006; Aziza, Abu-Bakr, Hertz-Lazarovitch, \&Ghanem, 2009); as well as independent activity among women to advance their own status (Weiner-Levy, 2007; Ussitzsky\& Lazar, 2009); and a rise in the value and significance of the nuclear family in comparison with the traditional extended family (Haj Yahia, Bargal\&Guterman, 2000).

The fact that young women are turning to higher studies and obtaining professional education and training is one of the functional expressions of the changes occurring in Arab society. Many parents encourage their daughters to leave 
home for a higher education. it places a heavy and meaningful responsibility on these young women for the family honor. It is primarily based on women safeguarding the accepted behavioral codes of a traditional society. Hassan (1999) distinguishes between "active" male honor, measured according to his achievements, his courageous behavior and his generosity, and "passive" female honor dependent on maintaining the behavioral code of obedience, conservatism and modesty. Kamir (2004) suggests that the concept of "a society of dignity" is a society in which a man's most important possession is his dignity, even dearer to him than his life.

\section{The Research Population}

The article is based on interviews which took place with sixteen Arab students in institutions of higher education in the north of Israel. Eight of them live in the area of Nazareth and the surrounding villages, five live in the bloc of settlements around Arrabe and Sakhnin, and three live in Arab villages between Akko and Tzfat. At the time of the interviews the students were in their twenties (the oldest among them was 26), unmarried and only two were engaged.

\subsection{The family background of the interviewees}

All of the interviewees are Muslims. The distribution of their stage of academic studies indicated that three had completed their first year of studies, five had completed their second year of studies and eight were in their last year of studies, leading up to a Bachelor's Degree. Nine of them had changed their course of studies during the first year. The young women stated that their parents had recognized the significance of a higher education and had encouraged them to leave in order to study. This encouragement was expressed in guidance and advice regarding the desirable area of studies to be chosen, assistance in registration and in carrying out the formal requirements of the academic institution and aid in financing studies and in paying rent.

The choice of interviewees was made using the purposive sampling method, according to which the sample is composed only of a population of those who are of special interest. For this research, we were seeking a sample of young Muslim women who were not married and who were required to change their place of residence in order to study.

\section{The interview}

The interviews took place during 2010-2011. They were conducted in Arabic, at the residences of the interviewees used during their studies. Ten of the interviewees live in rented homes and six live in student dormitory apartments. During the interviews, roommates were not present so that the discussion could be conducted in a comfortable atmosphere and with complete privacy. After transcription of the text of the interviews and preliminary identification of findings, an additional interview was conducted for a shared examination of what the students had said, and in order to receive the reactions of the interviewees to the interview findings.

The interview questions were semi-structured and open-ended. In the first part of the interview, the students were asked to tell the story of their lives as young women, high school graduates leaving home for academic study. They were requested to talk about leaving home and the move to academic institutions far from their homes. In the second part of the interview, open questions were posed to determine what, in their opinions, the important events were, in connection with their leaving homes for academic study and what their feelings were at the beginning of their studies. For any further explanations of the methodology of the interview, please see Gilat and Hertz-Lazarovitch (2010). Analysis of the interviews included investigation of structure and content of the stories told by the interviewees, identification of the main logical structures and examination of similarities and differences in the various interviews.

Findings were organized according to parts of interviews, and analysis of the life stories of the interviewees, in accord with the narrative approach, examining the story, relating to behaviors, values, and unique characteristics of the interviewee as expressed in her story and her descriptions of her coping with her situation (Gilat\& Hertz-Lazarovitch, 2006; Spector-Marzel, 2008, pp. 221-228).

\subsection{Findings of the Analysis: Different Dimensions of Exposure and Coping}

The students' answers to the second part of the interview were defined by us as the "dominant story" of each of them (Gilat and Hertz-Lazarovitch, 2006). An examination of the students' stories reveals that in many of them, descriptions emphasize the difficulties in being separated from their families: homesickness for their families and homes, a sense of 
empowerment from the independence demanded of them in their new places, and the significance of being exposed to a new and unfamiliar world with which they had to cope.

In G.'s story, the absence of her family in her new world was striking.G. asserted:

This is the first time that I had actually left my home. During the first period, I was really lonely. I missed my family, I was very homesick. I didn't know how to manage. Suddenly had to do everything alone: looking for an apartment, paying municipal taxes, buying food. There are so many errands that I didn't know about, and I also didn't know the language very well.

Later in the interview, she said:

My family helped. They gave the money for my studies. My father paid the rent on the apartment and organized it. But they couldn't help me every day. That was my job; if I wanted to study, I had to get organized. It's the independence which is so different than what I had known at home in the village.

Another student stated:

Missing my home and my family was the most difficult thing at the beginning. I felt as though my life was empty, lacking. It's not like home; the distance from the family makes the student more independent, responsible, and it improves self-confidence, but that takes lots of time. I would sit and prepare lessons to forget my longing for my parents.

In the second part of the interview, they were asked questions which investigated their feelings and their emotions with regard to the meeting with the academic institution and how they coped with these feelings. The students were asked whether it would be correct to say that the move from the home to the new place for academic study exposed them to an unfamiliar reality and what the significance of that reality was for them. From their replies, it can be seen that leaving the village represented a novelty for many of them.

Their descriptions indicate that they felt exposed in their new places with regard to three different dimensions: The first was the noveltydimension; They were exposed to new and unfamiliar places. The large number of regulations and behaviors that were unknown to them created tension and difficulty; The second dimension was the sense of "otherness", cultural exposure of a minority group member due to language difficulty: the problem of understanding the language, the ability to express yourself in what was not one's native language, the fear to actively participate in the lessons and the continual worry that the students did not understand, and were not even understood. Another context of their cultural exposure is associated with their being representatives of a national minority group living alone in places where the permanent residents were usually Jewish. The tensions between the groups create fear regarding how they would be seen, how they would be treated and what qualities would be attributed to them as members of a minority with which there are both religious and national tensions; The third dimension involves gender gaps, referring to genderdependent social exposure, at the basis of which are expectations of traditional gender roles which determine the balance of power in favor of male students. The student interviewees brought up descriptions of social tensions and pressures, against a gender backdrop. As the students come from a traditional patriarchal society which emphasizes family honor, they are under constant surveillance, supervision and inspection by other Arab students, both men and women, at the academic institution. These tensions derive from the threats, the silencing, the social supervision which set limits on their movement, keep them silent, and are the source of severe personal pressure.

Regarding the dimension of novelty, one of the students said that she had felt this strongly in the days before her studies had begun, as she was getting organized:

I felt like air, walking, not understanding, no one paying any attention to me, not belonging at all. I didn't know where I had to go, what I had to do, where the lesson was, what the number of the building was. I felt nothing, just really not belonging.

In another interview, N. described her first day: 
The bus stopped, we got off, my friend and I, and we began to understand where we were. Everyone was running, everyone knew where they were going - only we didn't. We stood facing the gate. We had to open our bags for the guard at the gate. I wanted to go back, to get on the bus and to return home. I felt that I didn't have anything to do there. I would never in the world succeed in getting along in such a place. I was ashamed to say that I didn't understand and that I didn't know where to go.

Another student, H., talked of feeling exposed when referring to how she felt during lectures and difficulties with the language, saying:

When they asked questions during the first days I would disappear, try not to be seen so that they wouldn't ask me. I didn't want to answer, with my Hebrew - I was embarrassed. I could answer with mistakes, how would the lecturer react? How would the class react? Those were the most stressful moments in the class.

In her interview, another student mentioned the fear of meeting with the majority group members:

There is no transportation to the college. You have to hitch rides from the intersection to the college. In the village, I never would have done that. Suddenly here I just had to. I stood on the side. I was afraid of being an Arab who was standing at the intersection. If Jews stopped, what, would I get in? I had never in my life been in a car alone with Jews...

An analysis of the students' stories indicates that, at the first encounter with the college or in the residence, they were not alone. A member of the family or a good friend accompanied them and their roles were to make the first encounter easier, and to help and to support the students in getting organized. Nevertheless, the students felt that they were coping with the new reality alone. This was expressed in the discrepancies between their descriptions of the reality they were dealing with and their descriptions of themselves in the reality. In their descriptions of the new place, and in their feelings regarding the majority group, the use of the third person plural is striking. When describing themselves, they use first person singular. This occurs despite the fact that, in their accounts, there are additional participants, such as a friend or a close family member. The gaps between the content of the stories and the usage of the third person plural indicates the students feelings and their loneliness in having to cope with the new place they had reached in order to study.

The feelings among the interviewed students that they were exposed in their own group, that is, other men and women Arab students, were expressed in a number of descriptions. One of the students told the following story:

Once I was standing and waiting for a bus. The bus didn't come and many cars had students in them. They had hitched rides - I don't hitchhike myself. Suddenly, while I was standing there, I saw one of our cars passing. Inside were students that I know and they didn't stop for me. I thought to myself, what are they thinking about me now... how did I look to them, standing at the intersection and waiting for a ride?

A. interpreted the tension between men and women students, saying:

There is also jealousy. Those who weren't accepted for studies, who don't succeed, out of jealousy they suddenly say, "Did you see her. She's meeting someone..." That's the way it starts and it goes from them on to others and then, on to others and who knows where it will end. One girl tells the next girl and it is passed on and on and it didn't actually happen. It can get to the village, to your uncles and cousins, to the family. It's not funny; It really is a serious matter. It harms your reputation as a girl. It harms your parents. They believe in you, expect that you will study; they think that you are sitting and studying and you come and show them your marks and you are succeeding and then, suddenly, they start to talk in the village about how you are acting and who you are meeting... I know more than one student to whom that happened. And it all began with the jealousy of someone who also registered for studies and didn't succeed so she begins to talk and to say things that never happened at all.

An analysis of the students' narratives brings out the characteristics of their feelings of being exposed and the loneliness in which they find themselves due to the surveillance and the supervision with which they must contend. In 
their accounts as well, there is a salient difference between the descriptions of the students themselves in the singular and the descriptions of the group which is always defined as third person plural. Even in the group in which they would be assumed to feel belonging and security, they feel isolated. The source of this feeling is in the informal surveillance and supervision exerted against them, especially on the part of male Arab students who are studying with them.

The verbs which reappear in the students' stories are: checking, speaking, passing on, testing, seeing, and looking. A map of these verbs and the numerous times they are used illustrates the control characteristics and the power of the social pressure applied to these Arab women students by the male students. These verbs express control, silencing, and the objectification these students experience and emphasizes the power the male students hold in the traditional social system, and which is used by them in order to continue to enjoy the power and the control they apply over the young woman students. This control is informal and includes systems of surveillance and supervision, limiting both dress and behavior. These are accompanied by intimidation and by the women students' sense that they are threatened in their personal and family contexts.

Additional interviews were conducted with the students after the transcription of the original interviews and their organization into structures of signification. The students were requested to retrospectively examine the findings from their stories and their feelings as women students who were dealing with the difficulties involved in leaving their homes for academic study. They were asked what, in their opinion, was the effect of their coping with the difficulties they had described, at the beginning of their studies and what the effect was of their leaving home for higher studies on their goals, intentions, values, beliefs, aspirations, obligations and dreams for the future.

In their replies to these questions, the use of terms expressing empowerment and inner strength were salient. These were prominent in the present context - as students experiencing success and also in the future context of young women in a traditional culture. Astudent stated that "I feel that I know more, that I can do more, that I have strength. Studies give you strength...Studies give you a good place to be".

A. connected her successas an event of her nuclear family:

When I finished the first year and I showed my parents my grades, I saw that my father was proud of me. I had succeeded. In his view, it says about him that he has succeeded. To him, my marks were his success. Here, he had brought up a splendid daughter, successful, so he as a father had succeeded.

Three students in their last year of studies expressed the significance of success as a way to independence in the future. In her answer, S. emphasized:

For me, time studying is successful time. I know that my studies will give me success in the future.... All the science subjects were difficult for me. I feel that if I succeeded in my studies, I can succeed in other areas. The studies are only an opening. Now that I am finishing, I have to begin a new way, working and earning my living.

In answer to the question, Ay.presented a comparison between her situation as one who has studied, and that of her mother and her sister at home:

Life was difficult. There were problems with my father. His life is not easy, he doesn't have work. My mother really works hard and she doesn't have the ability to support all of us. It's really difficult. It is a life of problems. There were many many problems. And since I left to study, I feel that I have a chance for a different life. I am outside the home. I am advancing towards a profession, towards earning my living. I am advancing and opening a door to the future, to life with a profession that will advance me.

Regarding the situation of social control forced on them by male students, the gender group of young women students serves as practice in dealing with constant surveillance, threat and exploitation. On the one hand, this practice expresses values of obedience and acquiescence, but in parallel, it enables the students to organize spaces of freedom and activity which considerably reduce the intensity of social control to which they are exposed.Makes it easier for them to deal with the inter-culture gender conflict between tradition and modernity, between power and weakness, which characterizes the discourse with them.

Relating to the social marginality of the control over them, R. described the motives for this supervision and control: 
I feel that the eyes that are looking at me and examining me derive from jealousy. It's not to supervise me. I don't need anyone to watch over me. I know how to take care of myself alone. They say that it is important to check that the girls don't fall in their new place. That's not the truth. It's because of jealousy. They (the practical engineering students) didn't succeed in being accepted into my track. That makes them small so they have a way of making me small from their own place, the fact that they feel that they have to guard me; they make me small because they threaten me.

Another student (S.) related to the significance of a group of girls as having force in their opposition to supervision and the group in empowering the women students:

The group represents real friendship. It gives us strength and security. If we do homework together, again explaining to anyone who didn't understand, in this way she succeeds and we all learn and that strengthens us, increases our strength in the class. Also when facing others in our studies, it is power = there is always someone who sees me. They can't say that she was walking alone, that she met someone and things like that, because someone who is with me knows what I did, where I am going and with whom I am meeting. So they have lost their power over me.

Another description relating the practices of a group of young women as neutralizing social pressure from the group of male students can be found in P.'s account:

My parents know that they are friends from my studies. We travel together, we also meet outside of studies. I think that even for my parents that is better, because I am not alone there. I have people to be with. They trust me and they also trust my friends. They see that they are dressed correctly, that they also come to study.

This description emphasizes the significance of the social group as a means to deal with tensions between the traditional society from which the young women have come and the stumbling blocks which may be in a student's way in the meeting with the modern society in her new place. The student's group of friends responds to the needs of the student's family and thus, neutralizes the significance of the social supervision and control.

In summary, it can be said that the findings indicate the significance of the nuclear family among young women in a traditional society in the process of change. Leaving the village involves difficulties the source of which is being far away from the family and from the home, and moving to a new place, far away and alienated. In the context of academic studies, the findings illustrate that the students feel vulnerable. This is expressed in a wide range of aspects: the first is associated with the sense of foreignness as women of a minority national group at their academic institutions and in their new residences. The second is connected to the difficulties with language, not being fluent and fear to express themselves in Hebrew in front of lecturers and other students. The third is connected to social life and it relates to the social relationships and the alignment of gender forces between the group of girls and the male students. In this context, they are exposed to intimidation, threats and pressures, the source of which is in the ability of the men to report about the young women's behavior and lifestyle to members of the extended family and others who have remained in the village. Examples of this reality appear in many interviews, and they demonstrate informal processes of social supervision and control regarding gender, the source of which is in male power in a traditional collective society. This supervision and control are carried out by the male students of the group, who appropriate informal roles for themselves which are based on the tension and fear of the female students that information about their behavior in their new places, in the academic institution, will be reported in the village and will damage their good names, their reputations and those of their families. The findings show that social organization among the young women is a practice of opposition to the silencing and gender coercion applied to them.

\section{General Discussion}

The life stories of the Muslim women students studying far from their homes indicate that, at this stage, academic studies are a means of personal advance for young women in a traditional society. Personal advancement and self-development are a way for young Arab women to develop independence and to promote change in the balance of gender forces 
existing in traditional Arab society. This is expressed in the women's descriptions of their aspirations for the future and the significance of their studies as a means of achieving these aspirations. In their stories, success and personal advance were salient and less so, success and growth in the context of the traditional family. Nevertheless, a number of expressions appeared in the students' stories which illustrate the significance of their success for the family. Their success is presented as family success. Parents encourage the interviewees to develop themselves and to have independent professions and thus, redefine what their correct lifestyle is. This is a different way of life, unknown to many - expressing processes of change in the traditional society to which the young students belong.

The nuclear family, the parents of the student, is perceived as providing physical, moral and spiritual support for the young women. Parents are viewed as encouraging and urging the women to study. The studies are seen by parents as a means for future independence of the women in a traditional society. However, the parents are also described as having expectations from the students which they must fulfill. Some of them pointed out that the source of their desire to succeed in their studies derived from their desire to satisfy their parents and to meet their expectations.

The significance of the family and the students' connections to their families become clear in the descriptions of the students' first days of loneliness and homesickness which were raised in the students' descriptions of their first days after leaving their homes and getting used to the new life as a student. Like the research of Haj Yahia, Bargal\&Guterman (2000), of Kolich and Ryan (2005) and of Pesta Schubert (2005), here too, the significance of the nuclear family as a source of support and empowerment was salient in the students' stories. The practical and moral support during their period of study facilitates student coping with the difficulties and even encourages and advances the students in leaving the circle of dependence and becoming independent. The dialogue with the community exists with emphasis on the change in the future status, future independence and future ability of the women students as significant for the family and less so for the community. Nevertheless, as Ossitsky Lazar andAbu-Baker have pointed out, it is clear to us that these processes of change are multidimensional, and are significant simultaneously for the family and for the community (AbuBaker, 1985; Ossitzsky Lazar, 2008).

An additional form of exposure for the interviewees is in the social realm and deals with relations with others, and primarily Arab men who have studied with them. From the life stories of the interviewees, a difficult even violent reality emerges, the essence of which is a system of surveillance and social and gender control, accompanied by threats and harassment by men students who take upon themselves the roles of supervision, inspection and control over the women students' activities, their lifestyle and their dress.

The philosopher Michel Foucault (1993) explained, "The body is also directly involved in a political field; power relations have an immediate hold upon it; they invest it, mark it, train it, torture it, force it to carry out tasks".In other words, the body is disciplined. How the body is related to is culturally determined and it is a direct result of tendencies and attitudes of society, which subjugate its form in accord with accepted norms.

In the stories of the interviewees, a reality exists of threat, intimidation and exploitation, and silencing, as well as social surveillance. The male students take advantage of informal systems the source of which is in traditional society and their task is to narrow the moves of the female students, to depress them and to rule their lives. This violent male control affects the daily behavior of the female students in strictly maintaining the values of modesty and tradition, on the one hand, and on the other hand, arouses fear and great concern with family reputation.

The departure of young women from the village for an academic education places them at the center of the tension which characterizes a society in a process of change. The system of social control illustrates the difficulties and tensions existing between the traditional way of life of Muslim religious society and the modernism which characterizes their new place. The threat, the intimidation and the silencing applied against the women constitute preservation and transcription of the balance of patriarchal power in favor of the men students, which negates the processes of change which are taking place.

The traditional patriarchal structure takes on additional significance when the young women are threatened. Much research testifies to the fact that women tend to base their sense of self evaluation using norms and standards of society more than do men. Their sense of self-identity is dependent on reactions of other people and requires continuous validation (Thøgersen-Ntoumani, Ntoumanis, Cumming \&Chatzisarantis, 2011). As a result, the woman feels that she has value only when others value and respect her, a situation in which herself evaluation tends to greatly fluctuate. Any rejection or failure is liable to lead to harm in her self evaluation, and accordingly, to chronic anxiety in significant areas for her. For this reason, researchers propose that an individual whose self-evaluation depends on external cultural ideals is expected to be more anxious and have a negative evaluation of his/her appearance. This person has greater chances of exhibiting compulsive behaviors regarding his/her appearance and his/her weight, in order to suit him/herself to the ideal of beauty and the defined standard (Thøgersen-Ntoumani et al., 2011). 
Similarly, Tamar Rapoport (1993) found that both among young people from well-to-do families and also among those from distressed economic backgrounds the "sexual reputation" factor plays a role. Behavior which is considered "unrestrained" receives external supervision and has a strong public dimension. The good name of the young girl and the good name of others connected to her (like her family) - are one. The limits change from context to context. For girls from secular well-to-do families the borders are flexible and more permissive, and the personal interpretationsis different. Their behavior is interpreted as exceptional, reversible and temporary, while those from distressed families see it as a personality feature which cannot be reversed and which is deserving of personal and collective punishment. This significant difference turns the social supervision and control into a real threat in the life of the young Arab woman student.

Examining the actions students adopt in order to deal with this reality illustrates two way of coping. The first is obedience and placation of the nuclear family. This practice is characterized by safeguarding the values touching on the significance of the family for the women in traditional society. The second practice, in contrast with the first, is opposition. This includes student groups and social groups which function as support groups and "free spaces" while facing the threats and silencing of the male hegemony. The support and the solidarity among young women in a group is a social response to pressures and violence to which the women are exposed as young students far from their homes. The meeting between parents and the social group of young students encourages feelings of trust and security in the student's parents and thus, reduces the significance of the informal supervision and control and enables the students to neutralize the threats and intimidation applied to them for reasons of gender.

\section{Summary}

This article examined the life stories of Arab students who are required to leave their homes in order to acquire an academic education. The life stories of the students illustrate how complex the realities are for Arab women students who choose to study in institutions of higher education. Their stories indicate that achieving a higher education, they feel that they are exposed and vulnerable and that they must cope alone with a range of difficulties. Some of these difficulties are connected to their meeting with a new and unknown place, language unfamiliarity and problems in expression, dealing with situations which are sometimes incomprehensible to them, and study skills in a language which is not their mother tongue. In addition to these are the isolation from the family, the homesickness, and the need to manage in a new place as members of a religious and national minority.

An additional difficulty the young women must deal with involves social pressures, threats, silencing and intimidation which derive from informal supervision and control on the part of male students from their own group. These men have appropriated for themselves roles which are significant in a traditional society and they take advantage of this status by intimidating, threatening, silencing and demanding obedience from the women to their requests as is accepted in a traditional society.

These systems of control play two roles. The first is seemingly social, that is, to safeguard the traditional way of life from which the students have come and to "protect" them from a meeting with the modern world. The second role, camouflaged, yet greatly significant in everyday life is a desperate attempt by the young men to maintain their status and their traditional position of power in a society experiencing processes of change which are newly defining the status and power of men.

Thus, the establishment of social control over the female students grants the men mastery over women's lives and ascendancy over the agenda of those who aim for professionalization, independence and freedom of choice in their future lives. They are demanded to live a reality of obedience to the social mechanisms of surveillance, supervision and intimidation based on gender differences and the need of young men to maintain their status in a changing society. The life stories of the women students demonstrate coping with this situation and show the practice of friendship and cooperation between the female students. These practices grant women a sense of protection and support and constitute free spaces for activity within the reality of limitations which surround them on campuses and in the places they live.

Limitations of the research stem from the representative character of the sample. The research dealt with female Muslim students who had left their homes and were living away from their families during their studies. In order to receive a fuller picture of the population it would be necessary to interview students who had returned to their homes at the end of their studies as well as those who study in academic institutions in which a larger proportion of the students are Arabs. Perhaps in institutions where the percentage of Arab students it higher, there will be different life stories. An additional limitation has its source in the research focus of the interviews on particular subjects. The research aspired to investigate 
the life realities of the students, focusing on the meeting between the traditional and the modern. Yet another limitation is that the objective of the study affected the structure of the interview which was tailored to the subject being examined.

In this context, it should be mentioned that an existing difficulty in the encounter of the interviewed students with the transcribed text of the interview. Many of the students expressed opposition and even asked to take back what they had said during the interview, in particular regarding what was said about the social supervision and control to which they were exposed during their studies. One student described this in saying: "No, you don't understand that what I said then, I didn't mean that I was afraid. It isn't that way. Fear is not the right word. "Another student stated when facing the transcribed conversation: "These are things that can be understood in a number of ways. This was your understanding...I will correct you, because that is not my understanding. That is your understanding...but I will explain to you again".

Despite these limitations, it appears that the article demonstrates the difficulties which characterize young women students who are required to leave their homes for academic studies. These students must cope with being women of an ethnic and religious minority in a new place, with a new language and a new culture which are unknown to them. Another significant difficulty, derived from their being at the intersection between the traditional and changing, is coping with social gender mechanisms of supervision and disciplining of the women's actions and of their bodies by young men who aspire to maintain their traditional social power and to reproduce their traditional gender superiority. The space in which they choose to realize their mechanisms of subjugation and social silencing is one which considered problematic in the meeting of the young woman with modernity, far from her home and her nuclear family. It is actually there that the traditional society and the extended family receive their demonic dimensions, the source of which is in the fear of the surrounding modern society, the independence and the freedom of the student in her new place, along with the fear of lying reports which are liable to lead to harm to their reputations and to the reputations of the family. It appears that the practices of opposition described by the female students enable them to cope successfully with the mechanisms of gender oppression and discipline and to progress towards their objective, and to bring social change and personal change in their journey towards a life of economic independence, freedom of movement and the ability to choose and to decide on their future as women.

\section{References}

Abu-Asba, C. (2001). Dilemmas and Issues in Ethical Education in Arab Schools in Israel, in Yaacovlram, ShmuelShkolnikov, Yonatan Cohen and Eli Schechter(eds.), Crossroads, Values and Education in Israeli Society. Jerusalem. TheMinistry of Education, Office of the Chief Scientist, 441-479.

Abu-Baker, K. (1985). The Impact of Cross-Cultural Contact on the Status of Arab Women in Israel. In: M. Safir\& AL (eds.), Women's Worlds: From the New Scholarship. New York: Prager publications .pp 246-250.

Abu-Baker, K. (2005). The Impact of Social Values on the Psycology of Gender among Arab Couples: A View from Psychoteraphy. Israel Journal of Psychiatry, 42, 2.106-114.

Aziza, P., Abu-Bakr, Ch., Hertz-Lazarovitch, R., and Ghanem, A. (2009).Arab Women in Israel: A Picture of the Situation and a View of the Future. Ramot, Tel Aviv.

Bader-Aref, K. (1995). The Arab Woman in Israel Leading Up to the Twenty-FirstCentury. The New East, 27, 213-218.

Bolotin-Chachashvili, S., Shavit, Y., and Ayalon, Ch. (2002). The Broadening ofHigher Education and its Stratificational Implications in Israel 1980-1996.Israeli Sociology, 4, 2, 317-347.

Dagan-Buzaglo, N. (2007). The Right to Higher Education in Israel: A Legal andBudgetary Look.Adva Center.

Dwairy, M. A. (1998). Cross Cultural counseling: The Arab-Palestinian case. NewYork: The Haworth Press.

Efrati, N. (2004). The Study of Women and Gender in the Middle East: The Development of the Discipline and its Directions, in A. Banjo (ed.) Women in the Middle East Between Tradition and Change. Tel Aviv, Moshe Dayan Center, 134.

Foucault, M. (1993). The Repressive Hypothesis'. Theory and Criticism, 4.153-160.

Gamliel A. and Kahan, S. (2005). Lack of Fairness in University Acceptance: the Modern Version of the Fable, "The Poor Man's Lamb'", Megamot, 33, 3, 433-445.

Gilat, E., and Hertz-Lazarovitch, R. (2006). A Method from Interviewing and Analyzing Life Stories Based on the Narrative Therapeutic Approach in Kassen and M. Krumer-Nevo (eds.) Analyzing Data in Qualitative Research, Beersheba, Magnes - Social Sciences. 126-152.

Haider, E. (2006). The Book of Arab Society in Israel: Population, Society, Economy.Jerusalem, Van Lear Institute and Kibbutz Hame'uchad.

Haj Yahia, M., Bargal, D. \&Guterman, N. (2000). Perception of job satisfaction, service effectiveness and burnout among Arab social workers in Israel. International Journal of Social Welfare, 9, 201-210.

Hamisi, R. (2007). From an Opposing Public to a Participating Public - Model for Preparation of a Cultural Master Plan for Arab Settlements in Israel, Geographical Horizons, 68-69, 116-140. 
Hassan., M. (1999). The Politics of Honor: The Patriarchy, the State, and the Honor Killing of Women in the Family, in: DafnaYizraeli et al. (eds.) Sex, Gender, Politics. Tel Aviv, Kibbutz Ha'meuchad, 267-305.

Kamir, A. (2004). A Question of Repect: Israeliness and Human Respect. Jerusalem, Carmel.

Kolich, L. and Ryan, P. (2005). Partner Relations, Coping Strategies in a Home-Work Conflict and Emotional Welfare: A Comparative Study of Jewish and Arab Women.Megamot, 33, 4, 633-658.

Markus, H. Z., \&Kitayman, S. (1991). Culture \& the self: Implications for cognition, emotion\& motivation. Psychological Review, $98,2,224-254$.

Matsumoto, D., Takeuchi, S., Andayani, S., Kouznetsova, N., \& Krupp, D. (1998). The contribution of individualism collectivism to cross-national differences in display rules. Asian Journal of Social Psychology, 1, 3.147-165.

Ossitzky-Lazar, S. (2009).'Not Like My Mother': Women Empowering Themselves - The Case of Kfar Kara.Publication No. 9. Jerusalem. Hebrew University in Jerusalem and the Shasha Center for Strategic Studies.

Panso, O. (2009). Statistical Abstract of Israel, 2009. Central Bureau of Statistics Jerusalem.

Pesta-Schubert, E. (2005). I Go Out and I Make the World Real, See Things More Clearly: Women, Higher Education and Bedouin Society in the Negev, Megamot, 33, 4, 659-681.

Rapoport, T. (1993). To be A Young Girl: in the Experiences of Sexual Tension Between Socialization Institutions.Megamot, 25, 1, 45-63.

Seginer, R. (2001). Youth in Israel Making their Way to the Bagrut: Future Orientation, Megamot, 31, 2, 98-113.

Seginer\&Noyman, M.S. (2005). Future orientation, identity and intimacy: Their relations in emerging adulthood. European Journal of Developmental Psychology, 2, 17-37.

Shanel, Y., and Sofer, M. (2007). Integration of Arab Initiative in the Israeli Economy.Horizons in Geography, 68-69, 73-98.

Sheinin, Y. (2010). Summary Paper, Session on Economic Development of Israeli Arabs. The Israeli Institute for Economic Planning, Herzlia

Spector-Marzel, G. (2008). Sabras Don't Get Old. Life Stories of Senior Officers of the 1948 Generation. Jerusalem, Magnes, 221-228.

Stephens, N. M,. Markus, H,. R. Townsend, S, M. (2007). Choice as an act of meaning: The case of social class. Journal of Personality and Social Psychology, 93.5.814-830.

Thøgersen-Ntoumani, Cecilie and Ntoumanis, Nikos and Cumming, Jennifer andChatzisarantis, Nikos L.D. (2011). When feeling attractive matters too much to women: a process underpinning the relation between psychological need satisfaction and unhealthy weight control behaviors. Motivation and Emotion, 35 (4), 413-422.

Triandis, H, C.; Bontempo, R., Villareal, M, J.; Asai, M,. Lucca, N. (1988). Individualism and collectivism: Cross-cultural perspectives on self-ingrouprelationships. Journal of Personality and Social Psychology, 54. 2, 323-338.

Weiner-Levy, N. (2006). Changes in Identity Among Pioneering Druze Women in Acquiring Higher Education.Israeli Social Issues, 1, 5-35.

Weiner-Levy, N. (2007). Stepping on a Narrow Line: Life Tours of Pioneering Druze Women. Concealed and Revealed Aspects in the Lives of Druze Women Who Chose to Acquire Higher Education. Tel Aviv, Modan.

Ya'ar, E. and Shavit Z. (ed.) (2001). Trends in Israeli Society. Tel Aviv, Open University. 